Revista Destaques Acadêmicos, Lajeado, v. 11, n. 3, 2019. ISSN 2176-3070

DOI: http://dx.doi.org/10.22410/issn.2176-3070.v11i3a2019.2202

http://www.univates.br/revistas

\title{
AÇÃO ANTIOXIDANTE DO RESVERATROL NO TRATAMENTO DERMATOLÓGICO: REVISÃO DE LITERATURA
}

\author{
Juliana Maronn Ücker', Marinês Pérsigo Morais Rigo²
}

\begin{abstract}
Resumo: A pele, maior órgão do corpo humano, além de envolver a superfície externa do corpo, possui importantes funções como a termorregulação, proteção, percepção e metabolização. Com o passar do tempo, o organismo sofre mudanças fisiológicas e um dos temas de grande importância nos dias de hoje é o envelhecimento. Várias teorias tentam explicar este processo, entretanto, a teoria envolvendo radicais livres e espécies reativas de oxigênio é uma das mais exploradas. $\mathrm{O}$ resveratrol, um importante polifenol, presente especialmente na uva e seus derivados, vêm sendo amplamente estudado devido a seus vários benefícios à saúde, entre eles, a capacidade antioxidante. Diante disso, o objetivo deste trabalho é discorrer sobre a ação antioxidante do resveratrol no tratamento dermatológico. A pesquisa constitui-se de uma revisão bibliográfica, realizada por meio de buscas nas bases de dados Scielo, Google Acadêmico e PubMed, publicados entre 2003 e 2019, tanto na língua portuguesa como inglesa, no período de dezembro de 2018 a fevereiro de 2019, utilizando as palavras-chave: resveratrol, antioxidante, cosméticos e saúde. Estudos demonstraram que formulações contendo resveratrol obtiveram resultados benéficos, como a redução dos sinais relacionados ao envelhecimento. Além disso, o resveratrol também apresentou significativa superioridade na atividade antioxidante em relação ao butil-hidróxi-tolueno (BHT), um antioxidante sintético. Os dados existentes na literatura apontam a grande importância do resveratrol, principalmente por sua capacidade antioxidante. No entanto, é fundamental que se desenvolvam cada vez mais estudos para aprofundar os conhecimentos e expandir o uso deste ativo na área cosmética.
\end{abstract}

Palavras-chave: Resveratrol. Antioxidante. Cosméticos. Saúde.

1 Farmacêutica; acadêmica do curso de Pós-Graduação Lato Sensu em Farmácia Estética da Universidade do Vale do Taquari - Univates, Lajeado, RS, Brasil.

2 Professora do curso de Pós-Graduação em Farmácia Estética da Universidade do Vale do Taquari- Univates, Lajeado, RS, Brasil. 


\section{INTRODUÇÃO}

Maior órgão do corpo humano, a pele é um órgão complexo, constituída por vários tipos de células interdependentes. Possui importantes funções, como a termorregulação, proteção, nutrição, percepção e metabolização, além disso, envolve a superfície externa do corpo e desempenha ampla importância social e emocional (HIRATA; SATO; SANTOS, 2004; TOFETTI; OLIVEIRA, 2006; ROLIM; PERREIRA; ESKELSEN, 2013).

A pele é dividida em dois tecidos principais: a epiderme, que é a camada mais externa e tem como função atuar como uma barreira protetora contra o ambiente externo, bem como reter o conteúdo interno, especialmente água, eletrólitos e nutrientes, e um tecido conectivo composto da derme e da hipoderme, camada inferior contendo gordura. A derme proporciona resistência e é formada por tecidos conectivos fibrosos de elastina e colágeno (HARRIS, 2003).

Com o passar do tempo, o organismo sofre mudanças fisiológicas e um dos temas de grande importância nos dias de hoje é o envelhecimento, considerando o aumento da expectativa de vida da população e a procura de formas para retardá-lo. Além disso, o estilo de vida vem passando por muitas mudanças através da vida moderna, principalmente urbana, com a exposição à poluição, alimentação inadequada, ritmo de vida acelerado, estresse, entre outros (SCHALKA et al., 2016).

O processo do envelhecimento está relacionado à fatores intrínsecos (cronológico), bem como à fatores extrínsecos provenientes de fatores ambientais como radiação ultravioleta, tabagismo, obesidade, e levam ao aparecimento de modificações dos contornos e elasticidade da pele, como sulcos, dobras e rugas associados à flacidez, provocadas principalmente pelo fotoenvelhecimento (STEINER; ADDOR, 2014).

Várias teorias tentam explicar o envelhecimento, entretanto, a teoria envolvendo radicais livres e espécies reativas de oxigênio é uma das mais exploradas (RIBEIRO, 2010). A formação de radicais livres é um processo contínuo e fisiológico, cumprindo funções biológicas relevantes. Porém, a produção excessiva pode levar a danos oxidativos. $O$ equilíbrio entre os processos de produção e eliminação dos radicais livres é de extrema importância, pois o desequilíbrio entre esses processos é o que causa o estresse oxidativo, levando a formação de lesões oxidativas nas células, como danos ao DNA e proteínas. A lipoperoxidação, oxidação da camada lipídica da membrana celular, é um dos principais mecanismos de lesão (BARBOSA et al., 2010; HARRIS, 2003; SCHNEIDER; OLIVEIRA, 2004).

A exposição à radiação ultravioleta do sol gera radicais livres e estas radiações, ao alcançarem a pele, interagem com as células da epiderme e da derme, originando os processos degenerativos. A luz solar é constituída de ondas eletromagnéticas, com diferentes níveis de energia, e os danos causados 
podem ocorrer através da ação direta da radiação UVB ou UVA curto, ou por meio de reações que envolvem agentes fotossensibilizantes (SILVA et al., 2015; HARRIS, 2003).

Para evitar esses danos, o organismo possui um sistema de defesa antioxidante, que é comumente dividido em enzimático e não-enzimático. O sistema enzimático contém as enzimas superóxido dismutase, catalase e glutationa peroxidase, que agem por meio de mecanismos de prevenção, impedindo e/ou controlando a formação de radicais livres e espécies nãoradicais. Já o sistema não-enzimático é constituído por várias substâncias antioxidantes, que podem ter origem dietética ou endógena (BARBOSA et al., 2010; SCHNEIDER; OLIVEIRA, 2004).

O resveratrol, um importante polifenol, presente especialmente na uva e seus derivados, vêm sendo amplamente estudado devido seus vários benefícios à saúde. Entre eles, está a capacidade antioxidante (SAUTTER et al., 2005).

Produtos cosmecêuticos que contenham ativos antioxidantes específicos são fundamentais para prevenção de danos causados por fatores característicos à vida urbana moderna como a poluição, estresse emocional e dieta inadequada (SCHALKA et al., 2016). Diante disso, o objetivo deste trabalho constitui-se de uma revisão da literatura sobre a ação antioxidante do resveratrol no tratamento dermatológico.

\section{METODOLOGIA}

Trata-se de um estudo de revisão, realizado por meio de buscas nas bases de dados Scielo, Google Acadêmico e PubMed. Foram selecionados 27 artigos, publicados entre 2003 e 2019, tanto na língua portuguesa como inglesa, usandose o termos: Resveratrol, antioxidantes, cosméticos e saúde. Foram descartados artigos que não estavam relacionados ao tema e ao período pesquisado. Também foram utilizados livros. A referida pesquisa foi desenvolvida no período de dezembro de 2018 a fevereiro de 2019.

Tabela - Principais artigos utilizados em resultados e discussões

\begin{tabular}{l|c|l|l}
\hline \multicolumn{1}{c|}{ Título } & $\begin{array}{c}\text { Ano de } \\
\text { publicação }\end{array}$ & \multicolumn{1}{c|}{ Objetivo } & \multicolumn{1}{c}{ Resultados } \\
\hline $\begin{array}{l}\text { Avaliação da } \\
\text { estabilidade e } \\
\text { atividade antioxidante } \\
\text { de uma emulsão base } \\
\text { não-iônica contendo } \\
\text { resveratrol }\end{array}$ & 2009 & $\begin{array}{l}\text { Incorporação do } \\
\text { resveratrol em uma } \\
\text { emulsão base não- } \\
\text { iônica para avaliação do } \\
\text { perfil de estabilidade e } \\
\text { atividade antioxidante }\end{array}$ & $\begin{array}{l}\text { A utilização de resveratrol } \\
\text { tanto na sua forma de } \\
\text { extrato seco, como quando } \\
\text { incorporado a uma emulsão } \\
\text { base não iônica, demonstrou } \\
\text { relevante superioridade na } \\
\text { atividade antioxidante em } \\
\text { relação ao butil-hidróxi- } \\
\text { tolueno (BHT) }\end{array}$ \\
\hline
\end{tabular}




\begin{tabular}{|c|c|c|c|}
\hline Título & $\begin{array}{c}\text { Ano de } \\
\text { publicação }\end{array}$ & Objetivo & Resultados \\
\hline $\begin{array}{l}\text { Resveratrate protects } \\
\text { human skin from } \\
\text { damage due to } \\
\text { repetitive ultraviolet } \\
\text { irradiation }\end{array}$ & 2012 & $\begin{array}{l}\text { Avaliar na pele } \\
\text { humana, os efeitos } \\
\text { fotoprotetores do } \\
\text { resveratrate, um } \\
\text { derivado estável do } \\
\text { resveratrol, após } \\
\text { radiação UV repetitiva }\end{array}$ & $\begin{array}{l}\text { Os resultados mostraram } \\
\text { efeitos protetores contra } \\
\text { queimadura solar e o } \\
\text { bronzeado }\end{array}$ \\
\hline $\begin{array}{l}\text { Development and } \\
\text { Preliminary Cosmetic } \\
\text { Potential Evaluation } \\
\text { of Melaleuca alternifolia } \\
\text { cheel (Myrtaceae) Oil } \\
\text { and Resveratrol for } \\
\text { Oily Skin }\end{array}$ & 2016 & $\begin{array}{l}\text { Avaliar o potencial } \\
\text { de uma formulação } \\
\text { cosmética de filtro solar } \\
\text { para pele com tendência } \\
\text { acneica contendo } \\
\text { óleo de melaleuca e } \\
\text { resveratrol }\end{array}$ & $\begin{array}{l}\text { O produto apresentou } \\
\text { moderada fotoproteção } \\
\text { UVA e UVB, e parece atuar } \\
\text { no controle da acne por } \\
\text { múltiplos mecanismos, } \\
\text { envolvendo redução da } \\
\text { oleosidade, hidratação, } \\
\text { descamação e tamanho dos } \\
\text { poros }\end{array}$ \\
\hline $\begin{array}{l}\text { Uma nova proposta } \\
\text { para avaliação } \\
\text { de cosmecêutico } \\
\text { antioxidante no } \\
\text { tratamento da pele } \\
\text { afetada pelos efeitos } \\
\text { da vida urbana }\end{array}$ & 2016 & $\begin{array}{l}\text { Avaliar a eficácia } \\
\text { de uma formulação } \\
\text { contendo antioxidantes }\end{array}$ & $\begin{array}{l}\text { Resultados positivos, } \\
\text { como a redução de sinais } \\
\text { e sintomas relacionados } \\
\text { ao envelhecimento } \\
\text { extrínseco e favorecendo } \\
\text { a uniformização da pele e } \\
\text { redução dos poros }\end{array}$ \\
\hline $\begin{array}{l}\text { Formulations } \\
\text { Containing Curcumin } \\
\text { or Trans-Resveratrol } \\
\text { Increase Dermal } \\
\text { Thickness in Rats } \\
\text { Submitted to } \\
\text { Chemical Peeling }\end{array}$ & 2017 & $\begin{array}{l}\text { Analisar os efeitos } \\
\text { de formulações } \\
\text { contendo curcumina } \\
\text { ou trans-resveratrol } \\
\text { na recuperação e } \\
\text { rejuvenescimento da } \\
\text { pele de ratos, após } \\
\text { peeling químico. }\end{array}$ & $\begin{array}{l}\text { O tratamento tópico com } \\
\text { trans-resveratrol aumentou } \\
\text { a espessura epidérmica e } \\
\text { dérmica. }\end{array}$ \\
\hline $\begin{array}{l}\text { Human skin } \\
\text { depigmenting } \\
\text { effects of resveratryl } \\
\text { triglycolate, a } \\
\text { hybrid compound } \\
\text { of resveratrol and } \\
\text { glycolic acid }\end{array}$ & 2018 & $\begin{array}{l}\text { Examinar os efeitos } \\
\text { despigmentantes } \\
\text { de triglicolato de } \\
\text { resveratril (RTG) } \\
\text { um composto } \\
\text { híbrido derivado } \\
\text { da esterificação do } \\
\text { resveratrol com ácido } \\
\text { glicólico }\end{array}$ & $\begin{array}{l}\text { Demonstrou efeitos } \\
\text { despigmentantes em } \\
\text { participantes humanos }\end{array}$ \\
\hline
\end{tabular}

\section{RESULTADOS E DISCUSSÕES}

O processo do envelhecimento é influenciado pela genética, fatores ambientais e comportamentais, onde alterações morfológicas, fisiológicas e bioquímicas acontecem progressivamente. A pele tem sua capacidade de homeostasia diminuída, bem como alterações estéticas características (RIBEIRO, 2010).

Os principais resultados da ação das espécies reativas de oxigênio na pele estão associados ao envelhecimento, como a perda de elasticidade e a 
capacidade de retenção de água, tendo como consequências perda de maciez e viço e o aumento na rugosidade (HARRIS, 2003).

Atualmente, há um grande interesse no desenvolvimento de cosméticos com ação antioxidante, que são fundamentais para prevenção de danos causados por fatores característicos à vida urbana moderna como a poluição, estresse emocional e dieta inadequada (SCHALKA et al., 2016). A aplicação tópica de substâncias ativas antioxidantes pode proteger a pele contra o fotoenvelhecimento a longo prazo e também pode ajudar o sistema antioxidante da pele contra o estresse oxidativo (SCOTTI et al., 2007; ZILLICH et al., 2015).

O resveratrol, um polifenol pertencente à família dos estilbenos, possui importante capacidade antioxidante, e é encontrado principalmente em raízes do ruibarbo, uvas, amendoins e vinho. É uma fitoalexina, sintetizada pelas plantas em condições de estresse, defesa, radiações UV, entre outros (ROSA et al., 2017). Possui duas formas de isômeros: trans-resveratrol (trans 3,5,4'-trihidroxiestilbeno) e cis-resveratrol (cis-3,5,4'trihidroxiestilbeno) (SAUTTER et al., 2005).

Figura 1: Estrutura química dos isômeros trans-resveratrol e cis-resveratrol

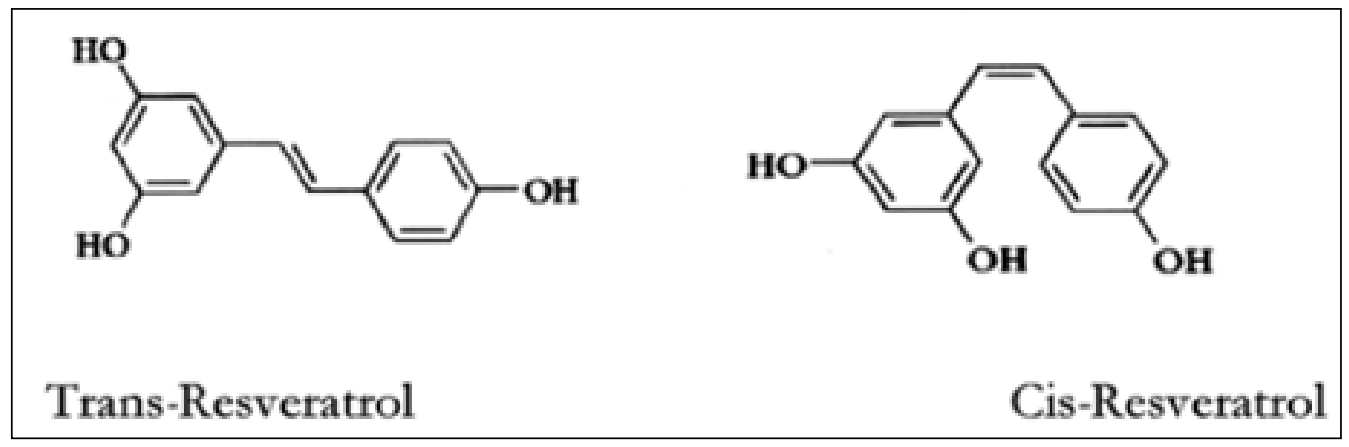

Fonte: Sautter et al. (2005).

Este polifenol despertou a atenção científica através do chamado "paradoxo francês", onde os franceses têm as mesmas taxas de colesterol dos americanos, entretanto, uma menor taxa de mortalidade por doenças cardiovasculares, e esse fato pode ser atribuído ao hábito francês do consumo de vinho após as refeições (LEAL et al., 2017).

O resveratrol está associado também à atividades anti-inflamatórias, antivirais, potente inibidor do crescimento apoptótico induzindo efeitos em várias células tumorais, efeitos sobre doença renal, neuroprotetor, melhora do perfil lipídico e prevenção de doenças cardiovasculares (ROSA et al., 2017; ALBERTONI; SCHOR, 2015). Segundo estudo de Oomen et al. (2009), o resveratrol apresentou efeitos benéficos sobre o cérebro, mantendo a saúde 
vascular cerebral, podendo contribuir para a preservação da função cognitiva durante o envelhecimento.

No estudo de Chang et al. (2015), ratos induzidos a aterosclerose foram suplementados com resveratrol, e observaram uma redução da massa de adiposidade e dos níveis de LDL-c, portanto o resveratrol pareceu suprimir a formação de lesão aterosclerótica.

Além disso, através da ativação da SIRT1, uma desacetilase dependente de $\mathrm{NAD}^{+}$, o resveratrol pode ter vários efeitos protetores contra distúrbios associados à idade. A SIRT1 pode regular múltiplas funções celulares, incluindo inflamação, apoptose, biogênese mitocondrial e adaptações ao estresse celular, através da desacetilação das proteínas alvo (KITADA; KOYA, 2013).

Nas videiras, o resveratrol é encontrado em espécies de Vitis vinifera e Vitis labrusca, e em vinhos tintos as quantidades encontradas são maiores em relação aos vinhos brancos e rosados (PENNA; HECKTHEUER, 2004).

Estudos apontam que polifenóis de uvas e vinho tinto previnem ou diminuem o estresse oxidativo através da atividade scavenger de radicais livres, aumento de antioxidantes endógenos, associação com a LDL-c aumentando sua resistência à oxidação, complexação com metais oxidantes, e através da modulação da atividade de enzimas-chave na defesa antioxidante (SOUSA; PEREIRA, 2013).

Em relação a pele, os polifenóis do vinho bloqueiam a ação da colagenase e da elastase, melhorando assim a microcirculação e hidratação, deixando-a mais elástica e consistente, e esses efeitos ocorrem por via tópica e oral (VACCARI et al., 2009).

Estudo realizado com um novo produto cosmecêutico, contendo resveratrol em microesferas combinado com os ácidos cafeico e ferúlico, e o extrato de blueberry, gerou resultados positivos, como a redução de sinais e sintomas relacionados ao envelhecimento extrínseco e favorecendo a uniformização da pele e redução dos poros (SCHALKA et al., 2016).

Segundo estudo de Lange et al. (2009), a utilização de resveratrol tanto na sua forma de extrato seco, como quando incorporado a uma emulsão base não iônica, demonstrou relevante superioridade na atividade antioxidante em relação ao butil-hidróxi-tolueno (BHT), um antioxidante sintético. Sendo assim, sua utilização pode ser uma alternativa viável em formulações cosméticas, devido ao seu grande potencial antioxidante. $\mathrm{O}$ resultado obtido pode ser explicado através da estrutura química da molécula do resveratrol, que apresenta dois anéis aromáticos e ligações duplas, formando intermediários relativamente estáveis, devido à ressonância do anel presente em sua estrutura. Já o BHT possui apenas um anel aromático em sua estrutura.

Da mesma forma, Baxter (2008) em seu estudo relatou que uma formulação à base de resveratrol teve atividade antioxidante 17 vezes maior que a idebenona, que também possui importante capacidade antioxidante. 
O resveratrol também demonstrou efeito protetor contra danos induzidos pela radiação UV. Wu et al. (2012) avaliaram na pele humana, os efeitos fotoprotetores do resveratrate, um derivado estável do resveratrol, após radiação UV repetitiva. Os resultados mostraram efeitos protetores contra queimadura solar e o bronzeado.

Oliveira et al. (2016) desenvolveram e avaliaram o potencial de uma formulação cosmética de filtro solar para pele com tendência acneica contendo óleo de melaleuca e resveratrol. O produto apresentou moderada fotoproteção UVA e UVB, e parece atuar no controle da acne por múltiplos mecanismos, envolvendo redução da oleosidade, hidratação, descamação e tamanho dos poros.

Já Gonçalves et al. (2017) analisaram os efeitos de formulações tópicas contendo trans-resveratrol ou curcumina na recuperação e rejuvenescimento da pele de ratos, após peeling químico. O tratamento tópico com trans-resveratrol aumentou a espessura epidérmica e dérmica. Este aumento da espessura dérmica pode ser atribuído à maior produção de colágeno, que pode aumentar a firmeza e elasticidade da pele.

O resveratrol também foi associado a possibilidade de ser um agente potencial de clareamento da pele para uso cosmético, segundo estudo de Lee et al. (2014) realizado em modelo animal. Já o estudo de JO et al. (2018) demonstrou os efeitos despigmentantes de triglicolato de resveratril (RTG) um composto híbrido derivado da esterificação do resveratrol com ácido glicólico. Vinte e duas mulheres participaram do estudo e nenhuma reação adversa foi observada. A ação antioxidante do resveratrol pode inibir a formação de melanina e realizar efeitos sistêmicos para o tratamento eficaz do melasma, uma hipermelanose comumente adquirida que afeta áreas da pele expostas ao sol (NA et al., 2019).

\section{CONCLUSÃO}

Os dados existentes na literatura apontam a grande importância do resveratrol, principalmente por sua capacidade antioxidante. Já existem no mercado vários cosméticos que contém em sua formulação o resveratrol, o que ressalta os seus benefícios na cosmetologia e no tratamento dermatológico. É fundamental que se desenvolvam cada vez mais estudos para aprofundar os conhecimentos e expandir o uso deste ativo na área cosmética.

\section{REFERÊNCIAS}

ALBERTONI, G.; SCHOR, N. Resveratrol desempenha importante papel no mecanismo de proteção na doença renal - mini-revisão. J Bras Nefrol, v.37, n.1, p. 106114, 2015. 
BARBOSA, K.B.F. et al. Estresse oxidativo: conceito, implicações e fatores modulatórios. Revista de Nutrição, v. 23, n. 4, p. 629-643, 2010.

BAXTER, R.A. Anti-aging properties of resveratrol: review and report of a potent new antioxidant skin care formulation. Journal of Cosmetic Dermatology, v. 7, p. 2-7, 2008 .

CHANG, G. et al. Resveratrol protects against diet-induced atherosclerosis by reducing low-density lipoprotein cholesterol and inhibiting inflammation in apolipoprotein E-deficient mice. Iran J Basic Med Sci, v.18, n. 11, p. 1063-1071, 2015.

GONÇALVES, G.M.S. et al. Formulations Containing Curcumin or Trans-Resveratrol Increase Dermal Thickness in Rats Submitted to Chemical Peeling. Journal of Cosmetics, Dermatological Sciences and Applications. v. 7, p.14-26, 2017.

HARRIS, M.I.N. de C. Pele: estrutura, propriedades e envelhecimento. São Paulo: Senac São Paulo, 2003.

HIRATA, L. L.; SATO, M. E. O.; SANTOS, C. A. M. Radicais livres e o envelhecimento cutâneo. Acta Farmaceutica Bonaerense, v.23, n.3, p. 418-424, 2004.

JO, D.J. et al. Human skin-depigmenting effects of resveratryl triglycolate, a hybrid compound of resveratrol and glycolic acid. International Journal of Cosmetic Science, v. 40, p. 256-262, 2018.

KITADA M.; KOYA D. Renal protective effects of resveratrol. Oxid Med Cell Longev, v. 2013, 2013.

LANGE, M.K.; HEBERLÉ, G.; MILÃO, D. Avaliação da estabilidade e atividade antioxidante de uma emulsão base não-iônica contendo resveratrol. Brazilian Journal of Pharmaceutical Sciences, v. 45, n. 1, 2009.

LEAL, J. B. et al. Resveratrol: Composição Química e seus Benefícios à Saúde. Revista Brasileira de Obesidade, Nutrição e Emagrecimento, v. 11, n. 67, p. 620-629, 2017.

LEE, T.H. et al. Inhibitory Effects of Resveratrol on Melanin Synthesis in Ultraviolet B-Induced Pigmentation in Guinea Pig Skin. Biomol Ther, v. 22, n. 1, p. 35-40, 2014.

NA, J.I. et al. Resveratrol as a Multifunctional Topical Hypopigmenting Agent.

International journal of molecular sciences, v. 20, n. 4, p. 956, 2019.

OLIVEIRA, C.S. et al. Development and Preliminary Cosmetic Potential Evaluation of Melaleuca alternifolia cheel (Myrtaceae) Oil and Resveratrol for Oily Skin. J Dermatol Res Ther, v. 2, n. 4, 2016.

OOMEN, C. A. et al. Resveratrol preserves cerebrovascular density and cognitive function in aging mice. Frontiers in Aging Neuroscience, v. 1, p. 1-9, 2009.

PENNA, N. G.; HECKTHEUER, L. H. R. Vinho e Saúde: uma revisão. Infarma, v. 16, n. 1-2, p. 64-67, 2004. 
RIBEIRO, C. J. Cosmetologia aplicada à dermoestética. 2. ed. São Paulo:

Pharmabooks, 2010.

ROLIM, M.E.S.; PERREIRA, M.A.; ESKELSEN, M.W. Envelhecimento cutâneo "versus" efeitos do resveratrol: uma revisão de literatura. Revista Eletrônica Estácio Saúde, v. 2, n. 1, 2013.

ROSA, M. de O. et al. O efeito protetor do resveratrol na doença de alzheimer. Revista Brasileira Multidisciplinar-ReBraM, v. 20, n.1, 2017.

SAUTTER, C.K. et al. Determinação de resveratrol em sucos de uva no Brasil. Ciência e Tecnologia de Alimentos, v. 25, n. 3. p. 437-442, 2005.

SCHALKA, S. et al. Uma nova proposta para avaliação de cosmecêutico antioxidante no tratamento da pele afetada pelos efeitos da vida urbana. Surgical \& Cosmetic Dermatology, v.8, n.1, p. 46-54, 2016.

SCHNEIDER, C.D.; OLIVEIRA, A.R. Radicais livres de oxigênio e exercício: mecanismos de formação e adaptação ao treinamento físico. RBME, v.10, n.10, 2004.

SCOTTI, L. Modelagem molecular aplicada ao desenvolvimento de moléculas com atividade antioxidante visando ao uso cosmético. Revista Brasileira de Ciências Farmacêuticas, v. 43, n. 2, 2007.

SILVA, A.L.A. et al. A importância do uso de protetores solares na prevenção do fotoenvelhecimento e câncer de pele. Revista Interfaces: Saúde, Humanas e Tecnologia, v. 3, n. 1, 2015.

SOUSA, M.S.; PEREIRA, M.C. de A. Mecanismos Moleculares de Ação Antiinflamatória e Antioxidante de Polifenóis de Uvas e Vinho Tinto na Aterosclerose. Rev. Bras. PI. Med., v. 15, n. 4, p. 617-626, 2013.

STEINER, D.; ADDOR, F. Envelhecimento cutâneo. 1 ed. Rio de Janeiro: AC Farmacêutica, 2014.

VACCARI, N. F. de S.; SOCCOL, M. C. H.; IDE, G. M. Compostos fenólicos em vinhos e seus efeitos antioxidantes na prevenção de doenças. Revista de Ciências Agroveterinárias, v.8, n.1, p.71-83, 2009.

TOFFETI, M.H. de F.C.; OLIVEIRA, V.R.de. A importância do uso do filtro solar na prevenção do fotoenvelhecimento e do câncer de pele. Investigação - Revista Científica da Universidade de Franca, v.6, n. 1, p. 59-66, 2006.

ZILLICH, O.V. et al. Polyphenols as active ingredients for cosmetic products. International Journal of Cosmetic Science, v. 37, p. 455-464, 2015.

WU, Y. et al. Resveratrate protects human skin from damage due to repetitive ultraviolet irradiation. Journal of the European Academy of Dermatology and Venereology, v. 27, p. 345-350, 2012. 